\title{
Effects of Substrate Material on Plant Growth and Nutrient Loss
}

\author{
Hao Yang ${ }^{1}$, Shaocai Li ${ }^{1}$, Hailong Sun ${ }^{2 *}$, Weiping Wang ${ }^{1}$, Fumei Zhao ${ }^{1}$ \\ ${ }^{1}$ Key Laboratory of Bio-Resource and Eco-Environment of the Ministry of Education, College of Life Sciences, \\ Sichuan University, Chengdu, P.R. China \\ ${ }^{2}$ State Key Laboratory of Hydraulics and Mountain River Engineering, Sichuan University, Chengdu, P.R. China
}

Received: 28 September 2017

Accepted: 7 December 2017

\begin{abstract}
We investigated substrate material and the effects of different fertilizers and water levels as variable factors for slope restoration. A field rainfall monitoring experiment was carried out to explore morphological changes in Amorpha fruticosa L., the water-holding capacity of its leaves under different water and nutrient gradients, and the nutrient losses from the substrate. The results showed that nutrient loss by runoff was significantly affected by fertilizer use and they increased with the increased application of fertilizers. The concentration of nitrogen in runoff was insignificant, the concentration of phosphorus was increased, and the runoff concentration of potassium was decreased after increasing water-retaining agent levels in the substrate. The concentration of nutrients in runoff from rainfall generally followed a trend of slight fluctuations, then a rise, and finally a decrease. The addition of F2 fertilizer produced the lowest nitrogen losses from substrate material and reduced the leaf area where the addition of phosphate fertilizer had a significant effect on crown diameter. At greater content of the water-retaining agent, the water in substrate material increased, resulting in increased water absorption by the plants and increased relative water content of leaves. Ultimately, W3F4 was the most favorable combination of water-retaining agent and fertilizer concentration for plant growth, which may be related to runoff losses. This combination provides optimal conditions under which the plant can maintain a perfect balance of nutrients and thus improve plant growth indices.
\end{abstract}

Keywords: substrate material, plant growth, nutrient loss, Amorpha fruticosa L., rock slope

\section{Introduction}

The number of road engineering and construction projects that create rock slopes has been increasing year by year, instigating a series of geologic hazards and ecosystem destruction such as landslides, mudflows,

*e-mail: hailongsun999@163.com

and so on. The ecosystems are thus in an urgent need for recovery and reconstruction. However, ecological restoration processes of rock slopes are more challenging compared to those of clay slopes because rock slopes are highly heterogeneous and do not provide favorable soil conditions for plant growth, especially due to the lack of nutrient accumulation and lower heat and moisture capacity [1]. Thus, rock slopes present complex and varied ecosystems that do not support plant growth. 
Since the current engineering construction practices have increased the slope of rocky sides (the slope ratio is $1.00: 0.75$ or above), the external erosion is obvious, which, along with complex geological types, impairs ecological protection [2], eventually slowing down the process of restoration and reconstruction of rock slopes. Therefore, it is necessary to establish a stable community and an optimized plant structure, which in turn improves slope stability and reduces soil erosion [3].

Amorpha fruticosa $\mathrm{L}$. is a perennial leguminous shrub [4] widely distributed in China, in the north, northeast, and southwest regions, the Yangtze and Yellow River basin, and other places. The species is about 1-4 m high and characterized by oval leaves and fast-growing fibrous roots with reticulate structure. Because this plant is highly adaptable and can endure unfavorable environmental conditions [5-6], it is a preferred plant for slope remediation and road afforestation. In recent studies on A. fruticosa, scholars have focused on the biotic community [7], cultivation [8], biological protection [9], chemical composition, nutritional value, and utilization [10-12], and physiological changes and adaptations under drought, salt, and low temperature stress conditions [1314]. In contrast, the correlation between water, fertilizer application, and growth characteristics of this shrub has rarely been studied.

The traditional slope remediation and reinforcementbased treatment use rigid professional tools, particularly for concrete breakwater and rock breakwater, which are characterized by good wear resistance, strong erosion resistance, and long-term durability, but also by high cost and difficult operation, as well as neglect of ecological values. Therefore, flexible protection methods - such as the use of plant roots to stop weathering and spalling - have been applied more frequently for slope stabilization. Different technologies have been used in green reconstruction of rock slopes, including thick layer base slope green technology [15], concrete biotechnical stabilization of slopes [16-17], and planting grass by spraying seeds [18-19]. These technologies implement companion planting, which not only stabilizes the slopes but also restores ecological balance. However, poorer water and fertilizer conservation, slower construction speed, shorter exposure time, and higher cost were substantial constraints on further development of these techniques.

Consequently, the selection of a slope material that will deliver the basic function of slope protection and conservation of water and fertilizer is a top priority. Substrate material, a new product characterized by improved water conservation, thermal insulation, low cost, and easy maintenance, has been investigated as a promising slope material [1, 20-21]. The application of substrate material involves two stages: engineering techniques to stabilize and reinforce the rock slope, and substrate material, which provides a reasonable physical structure, platform, or carrier for water and nutrients required for plant growth. Simultaneously, substrate material may lead to decreased water and soil losses and even effectively resist water and wind erosion. In the present study, a field rainfall monitoring experiment was conducted to investigate substrate material for reforestation in slope engineering by examining the effects of different fertilizers and water allocation on several morphological parameters, and the leaf waterholding capacity in A. fruticosa plants and nutrient loss from the substrate. The theoretical basis and technical support were developed based on the management of water and fertilizer by this species, which will help to improve the ecological restoration technology.

\section{Material and Methods}

\section{Materials}

The substrate material used in this study was provided by Sichuan Allvery Environmental Science Technology Co., Ltd. in Chengdu, China, along with the plant growth substrate, water-resisting layer, seed germination equipment, temperature adjustment layer, and radiant heat barrier (Fig. 1). The substrate soil was prepared by mixing purple soil, peat, water-retaining agent, quick-acting fertilizer, and slow-release fertilizer in the ratio 30:150:15:2:8. The water-retaining agent was prepared by Chengdu Yixin Chemical Co., Ltd. These poly(acrylic acid-co-acrylamide) hydrogels are a nonpolluting environmentally friendly product with a particle size of $0.5-1.0 \mathrm{~mm}$. The substrate material was placed on an artificial frame, which could be set to predetermined slope steepness (Figs 2-3). The basic properties of the soil are shown in Table 1.

\section{Experimental Design and Methods}

The rainfall monitoring experiments were conducted in an outdoor laboratory at the Engineering Technology Institute for Mountain Ecology, Pengzhou, Chengdu, China. The annual rainfall in this area is $1,146.50 \mathrm{~mm}$ and the main rainy season occurs from May to September. The background concentration of nutrients in the runoff was analyzed.

To simulate nutrient cycling in eco-engineered rock slopes, a runoff collector was set at the bottom of the plot to direct runoff into a collection bottle. The concentrations of total nitrogen, phosphorus, and potassium in the collected runoff were analyzed with a SKALAR automated analyzer (Breda, the Netherlands) using a runoff sample that was filtered through a $0.2-\mu \mathrm{m}$ filter paper. Plant height, leaf area (2/3 of lamina length $\times$ width) [22-23], and crown diameter of this shrub were measured using a ruler. Rhizome thickness was determined using a Vernier caliper, and branch and leaf number were determined by visual inspection. Each measurement was conducted in triplicate and analytical blanks were included for all determinants. All reagents used in this study were made in China. Hydrochloric acid ( $\mathrm{HCL})$, nitric acid $\left(\mathrm{HNO}_{3}\right)$, hydrogen fluoride (HF), and 


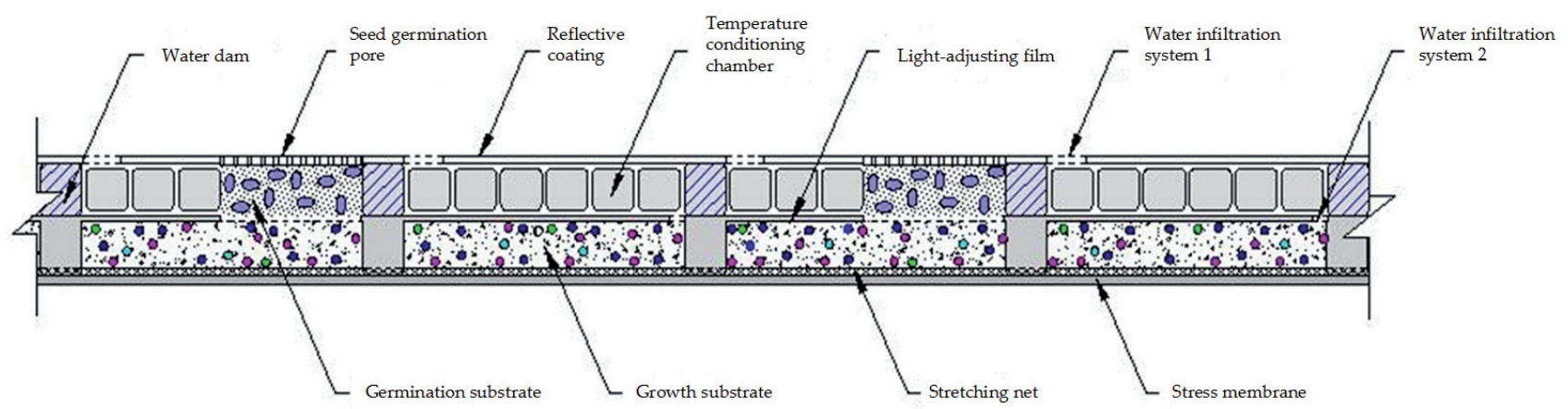

- Water particle $\quad$ Nutrient particle Growth regulator o Water retaining agent 0 Seed

Fig. 1. Structure of substrate material.

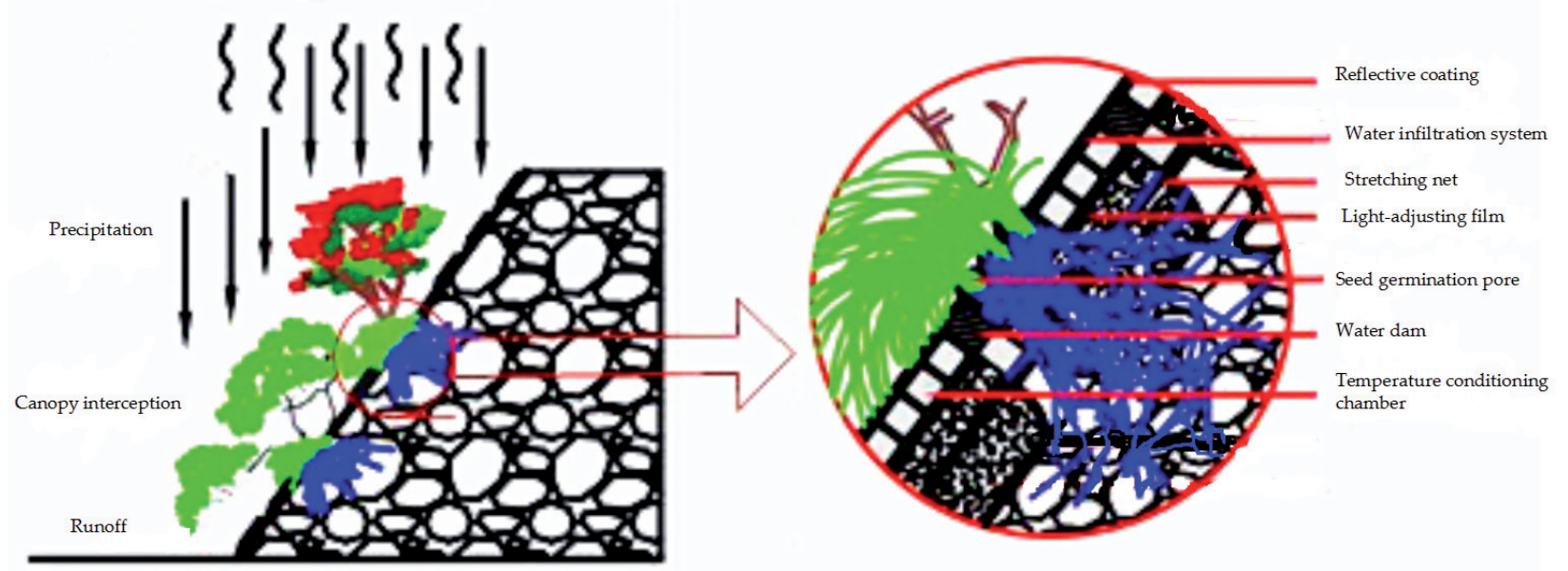

Fig. 2. Schematic diagram of the experimental setup.

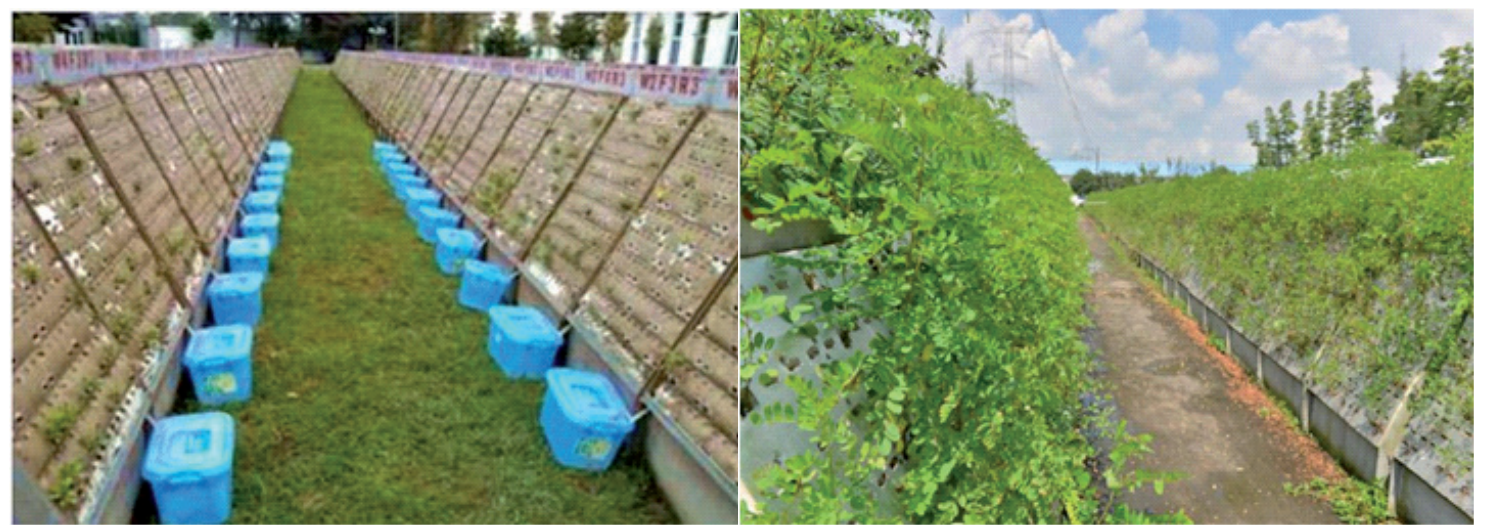

Fig. 3. A. fruticosa planted on substrate material at the Engineering Technology Institute for Mountain Ecology of Pengzhou, Chengdu, China.

Table 1. Physical and chemical properties of substrate material.

\begin{tabular}{|c|c|c|c|c|c|c|}
\hline $\begin{array}{c}\text { Bulk density } \\
\left(\mathrm{g} / \mathrm{cm}^{3}\right)\end{array}$ & $\mathrm{pH}$ value & $\begin{array}{c}\text { Thickness of the } \\
\text { material }(\mathrm{cm})\end{array}$ & $\begin{array}{c}\text { Total N } \\
\left(\mathrm{g} / \mathrm{m}^{2}\right)\end{array}$ & $\begin{array}{c}\text { Total P } \\
\left(\mathrm{g} / \mathrm{m}^{2}\right)\end{array}$ & $\begin{array}{c}\text { Total K } \\
\left(\mathrm{g} / \mathrm{m}^{2}\right)\end{array}$ & $\begin{array}{c}\text { Organic matter of purple soil } \\
(\mathrm{g} / \mathrm{kg})\end{array}$ \\
\hline 1.20 & 6.50 & 5.00 & 10.36 & 7.51 & 22.80 & 56.66 \\
\hline
\end{tabular}


perchloric acid $\left(\mathrm{HCLO}_{4}\right)$ were of reagent grade, and other regents were of analytical grade.

Five different gradients of fertilizer and water levels were adopted by orthogonal design for slope substrate material, with a total of 25 samples, namely W1 $(0.5 \times \mathrm{W} 3), \mathrm{W} 2(0.7 \times \mathrm{W} 3), \mathrm{W} 3, \mathrm{~W} 4(1.2 \times \mathrm{W} 3)$, and W5 $(1.5 \times$ W3 $)$, and F1 $(0.5 \times$ F3), F2 $(0.7 \times$ F3 $)$, F3, F4 $(1.2 \times \mathrm{F} 3)$, and F5 $(1.5 \times \mathrm{F} 3)$, where W3 $\left(18 \mathrm{~kg} / \mathrm{m}^{2}\right)$ and F3 $\left(300 \mathrm{~g} / \mathrm{m}^{2}\right)$ represent reference standards for water-retaining agent content and amount of fertilizer, respectively. The runoff samples were collected at the end of the natural precipitation and refrigerated for chemical analysis. The chemical composition analysis of the runoff samples was repeated 3 times in the same area and their average values were calculated. Data on the amount and chemical properties of rainfall were obtained from an automatic weather station.

To measure leaf relative water contents, leaf samples collected from $A$. fruticosa shrubs were weighed and subjected to a supersaturated water treatment until constant weight; weighing of the samples was conducted 4 times every $2 \mathrm{~h}$. Relative water content was measured according to the method described by Sadeghishoae [24].

\section{Statistical Analysis}

Collected data were analyzed and plotted in Microsoft Excel 2007 (Microsoft Corporation, Seattle, WA, USA) and GraphPad Prism 6 (GraphPad Software, Inc., La Jolla, CA, USA) using descriptive statistics. Regression analysis and one-way ANOVA were carried out using SPSS19.0 (SPSS Software, Inc., Chicago, IL, USA). Plant growth data were also analyzed using membership functions under different levels of water and fertilizer [25-26] according to the following equations.

Positive correlation between plant growth and water and between water level and fertilizer in substrate material (Eq. 1):
$\hat{\mathrm{X}}_{i j}=\left(x_{j}-x_{i \min }\right)\left(x_{i \max }-x_{i \min }\right) ;$ for $i, j=1,2, \ldots, n$

The mean value of the membership functions under different levels of water and fertilizer in A. fruticosa (Eq. 2):

$$
\bar{x}_{i}=\sum \hat{x}_{j} / n ; \text { for } i, j=1,2, \ldots, n
$$

where $\bar{x}_{i}$ is the mean value of membership functions of the $i$ th level for water and fertilizer in substrate material. Parameter values of $i$ are also introduced. Parameter values of $i$ and $j$ were determined experimentally.

\section{Results and Discussion}

\section{Losses from Substrate Material}

The content of soluble nutrients in the runoff originating from the fertilizer increased with increasing fertilizer concentration; there was a negative correlation between increased fertilizer application and the losses of substrate nutrients in the experimental group (Fig. 4a). Secretion from the roots and chemical composition of plant litter improved with increasing fertilizer concentration, causing a rise in the activity and migration of fertilizer nutrients. Therefore, reducing the amount of added fertilizer in substrate material is an important approach to preventing loss of nutrients due to runoff. However, at constant fertilizer levels but varied concentration of the water-retaining agent, nitrogen concentration in the runoff remained constant, while there was a significant rise in phosphorus concentration (Fig. 4b). Therefore, the increase in water-retaining agent improved phosphorus release and its effectiveness in the material, thus improving phosphorus uptake by plants

b)

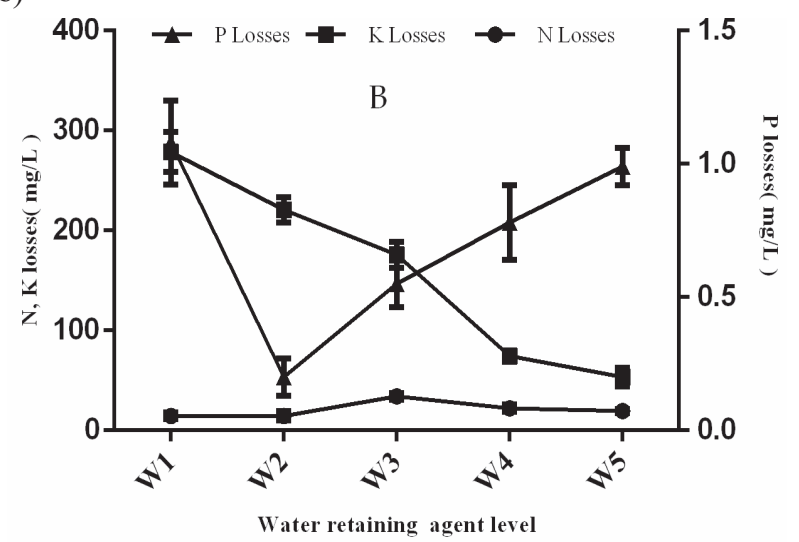

Fig. 4. Relationship between fertilizer, water-retaining agent, and nutrient runoff in substrate material: F1-F5 and W1-W5 represent 5 different gradients of fertilizer and content of water-retaining agent, respectively; uncertainty is represented as the standard deviation of the mean of 3 replicated plots. 
[27]. In contrast, the water-retaining agent treatments decreased the potassium concentration in the runoff samples.

Generally, nitrogen concentration in runoff samples was slightly altered or showed a slight increase and then decreased; this behavior appeared to be related to variation in moisture gradients. Phosphorus is easily fixed by substrate material [28], and therefore the loss of phosphorus from the substrate material was the lowest
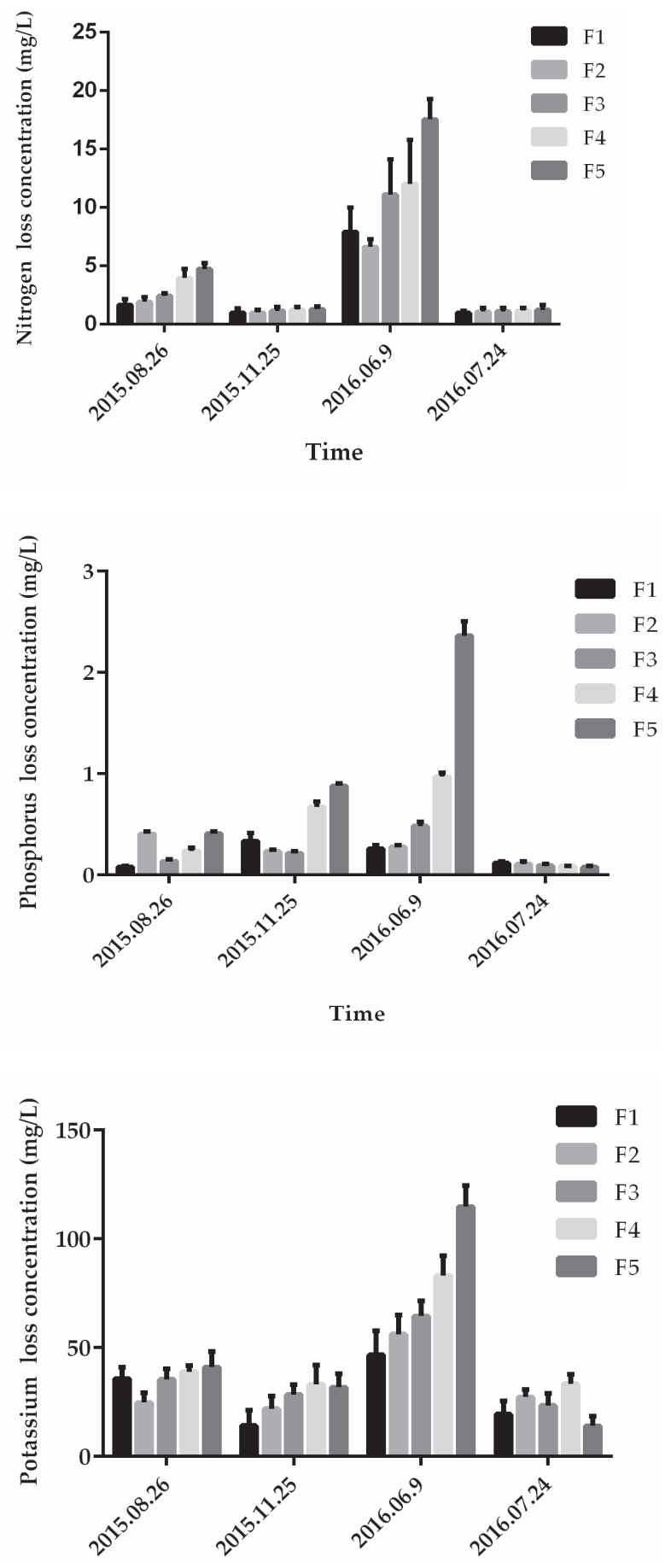

Fig. 5. Correlation between the amount of water-retaining agent, the concentration of nutrients in runoff, and the time of rainfall; columns represent least squares means while error bars indicate SD. at W2 levels of the water-retaining agent; its adsorption, immobilization, and interaction with substrate material were affected by the water-retaining agent. Meanwhile, the concentration of potassium in runoff was high at W1 and decreased with increasing levels of the waterretaining agent, suggesting that the greater amount of runoff generated at lower water-retaining agent concentrations contributed to the elution of potassium from the substrate material. Taken together, these results
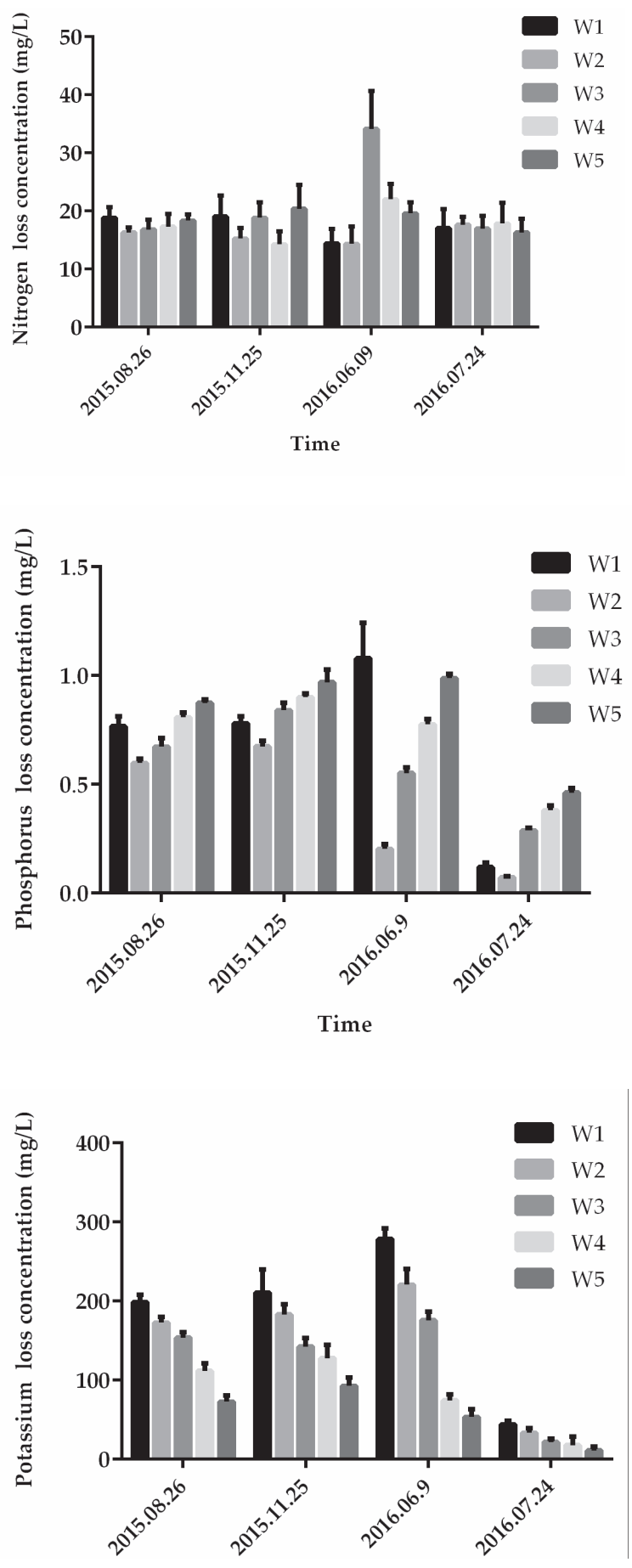

Fig. 6. Correlation between the amount of fertilizer, the concentration of nutrients in runoff, and the time of rainfall; columns represent least squares means while error bars indicate SD. 
indicate that the substrate material positively affects the fertilizer.

The runoff volume from the same substrate material at different time and intensity of rainfall was analyzed for nutrient concentrations (Figs 5-6). The results indicated that the runoff volume initially increased and then decreased. The nitrogen, phosphorus, and potassium concentrations in the runoff followed the same trend with prolonged rainfall period under different moisture gradients (Fig. 5). The present experiment commenced in summer, a period with no rain, and from the first rain event on 26 August until 25 November 2015 there were no significant changes in nutrient concentrations in the runoff as the rainfall infiltrated into the substrate. Nutrient leaching from the substrate was observed during rainfalls in the 2016 rainy season, which was probably related to longer rainfall events that were concentrated in summer months of 2016, saturating the surface soil to its maximum water capacity. The high concentrations of nutrients in the runoff in 2016 may be explained by increased loss of nutrients from the soil due to increased rainfall amount, intensity, duration, and frequency in the third rainfall event. One month later, this increased rainfall may have led to a decrease in nutrient levels in the runoff due to declining soluble nutrient content in substrate material after repeated showers.

Potassium concentration was significantly higher than the concentration of other nutrients at different fertilizer levels (Fig. 6). The processes involved in the regulation of soil nutrient losses indicate that potassium is not readily absorbed by soil and the water-retaining agent and can be easily lost from the substrate [29]. Therefore, potassium concentration remained nearly constant throughout the experimental period. In contrast, phosphorus is easily adsorbed even by soil colloids, while high nitrogen concentrations in runoff are related to urea hydrolysis. However, nitrogen sources (including $\mathrm{NH}_{4}^{+}$and urea) can be absorbed and dissolved by the water-retaining agent, and consequently, nutrient concentrations in the runoff from substrate material are stabilized after multiple rainfall events [30]. Thus, the results suggest that waterholding capacity of the substrate material is constant.

The results of runoff analysis after the four rainfall events indicate that there are many influencing factors and that they are mutually restricted as a result of nutrient loss. Nutrient losses from the substrate material are related only to the runoff losses, regardless of the level of soil erosion, because substrate material is a closed system with a stable structure; volume and nutrient concentration in runoff are major factors affecting nutrient runoff losses. Thus, the amount of fertilizer added to the substrate is mainly determined by the nutrient concentrations in runoff, whereas the level of nutrient losses is altered in surface runoff by the amount of fertilizer: the more fertilizer, the more the water-soluble nutrients and the greater the nutrient losses by runoff [31]. In addition, the effect of the water-retaining agent on nutrient loss from the substrate material was not significant, as indicated by the absence of a significant change in runoff concentrations at different moisture gradients during the first two measuring periods. During the first year of observations, the nutrient losses by runoff from the substrate material increased for those elements as a result of leaching from the surface soil during rainfall. In the second year of observations, the nutrient concentrations in runoff decreased and eventually bottomed out.

Nitrogen concentration in runoff was insignificant, that of phosphorus was increased, and the potassium concentration decreased with increasing water-retaining agent levels. These results may be related to the adsorption capacity of the water-retaining agent and the nutrient release and their migration characteristics in the substrate material. Therefore, migration characteristics of each element should be considered when developing a new nutrient design of substrate material for slope restoration. Nutrient loss has been attributed to poor absorption of nutrients and colloids in substrates, and thus the presence of major elements and the adsorption characteristics of substrate material need to be considered when choosing the right substrate. Meanwhile, the release and fixation of nutrients in substrate are affected by moisture. Continuous leaching of nutrients forms a condition of alternate drying and wetting, which influences fertilizer preservation by substrate material [32]. Nitrogen concentration in the runoff was not significantly altered by changing fertilizer concentrations in the substrate. A likely explanation for this is that nitrogen loss is affected by the form of nitrogen present in the substrate; leaching can occur once the nitrogen is converted to nitrate, which is then dissolved in runoff or adsorbed on colloidal particles and as such lost as inorganic and organic nitrogen [33]. How to dissolve this element by a water-retaining agent is an essential question that needs to be addressed by regulating the water balance. The water-retaining agent played a limited but significant role in runoff inhibition because it forms an adsorption structure that adheres to colloidal particles and substrate nutrients. Despite acting as an adsorption structure, the water-retaining agent did not prevent nitrogen leaching into runoff, which explains the lack of a significant difference between the treatments with different water-retaining agent content.

\section{Coupling Effects of Water and Fertilizer}

The coupling effects of water and fertilizer on plant growth rates are presented in Fig. 7. The increase in shrub height initially intensified with increasing fertilization rate under constant moisture level, reaching maximum levels at F4 $(15.4 \mathrm{~cm})$ and decreasing thereafter. The increase in height of $A$. fruticosa was greatest at W3, except for F2, indicating that the water-retaining agent improved water use efficiency [34]. The levels of water and fertilizer affect plant growth, particularly branch number [35]. At the highest levels of water-retaining agent (W5), the branch number was greater for each fertilizer level than that for other levels of water-retaining agent. Meanwhile, leaf area at F2 was effectively restrained by the addition of fertilizers, while leaf area increased with increasing 
fertilizer levels as the amount of water-retaining agent was maintained constant at W3. However, when the water retaining agent level increased to W3 under constant fertilization rate, leaf area gradually decreased in relation to the effects of the water-retaining agent on nutrients from the substrate material [36]. Rhizome is an underground part that supplies the plant with nutrients, and its size or thickness depends on nutrient and water status of the substrate material. Thus, when the fertilizer concentration in the substrate material was reduced to F2 levels, rhizome thickness decreased.

Generally, nutrient availability, not water level, is the major limiting factor for plant growth because the waterretaining agent in the substrate material can effectively absorb water. The results also show that height, leaf area, rhizome thickness, and crown diameter are the growth parameters of this shrub that performed the best at W3 water-retaining agent level and different fertilizer rates. If a water-retaining agent is added to the substrate material, these growth indices are gradually reduced. This observation indicates that an excess of water in the substrate material exacerbates nutrient and water absorption and thus affects plant growth [37]. Waterretaining agents in substrate material are thought to play a role in promoting plant growth, especially the number of leaves, which presumably results from the association between plant transpiration and soil water. The increase in stomatal aperture reduces water loss from the soil under sufficient water levels, because higher soil moisture relates to higher transpiration rate and lower water-use efficiency of plants [38]. Simultaneously, the branch number remained nearly steady throughout the experimental period.

Moreover, as fertilizer concentration in the substrate material continued to rise in F3, the rhizome reached its maximum size and its thickness increased by $1.14 \mathrm{~mm}$. The largest rhizomes were measured in shrubs at W3 water-retaining agent concentration and F3 fertilizer concentration in the substrate material. The number of leaves was the highest at F3 fertilizer concentration, and it decreased with further increase in fertilizer concentration. In contrast, the number of leaves increased with increasing water-retaining agent levels at constant fertilizer levels. Therefore, water and fertilizer levels in the substrate material have an important role in promoting the growth of this species, particularly crown diameter. Therefore, at W3 water-retaining agent content and F4 fertilizer concentration, the crown reached its maximum diameter and decreased with further increase in the concentration of these two parameters.

Besides playing a role in nutrition, water is an important factor for prolonged preservation of substrate material and plant growth. Plant height, branch number, leaf area, and crown diameter of $A$. fruticosa reached the highest values at F4 fertilizer concentration, and further increases in fertilizer levels resulted in gradual decreases
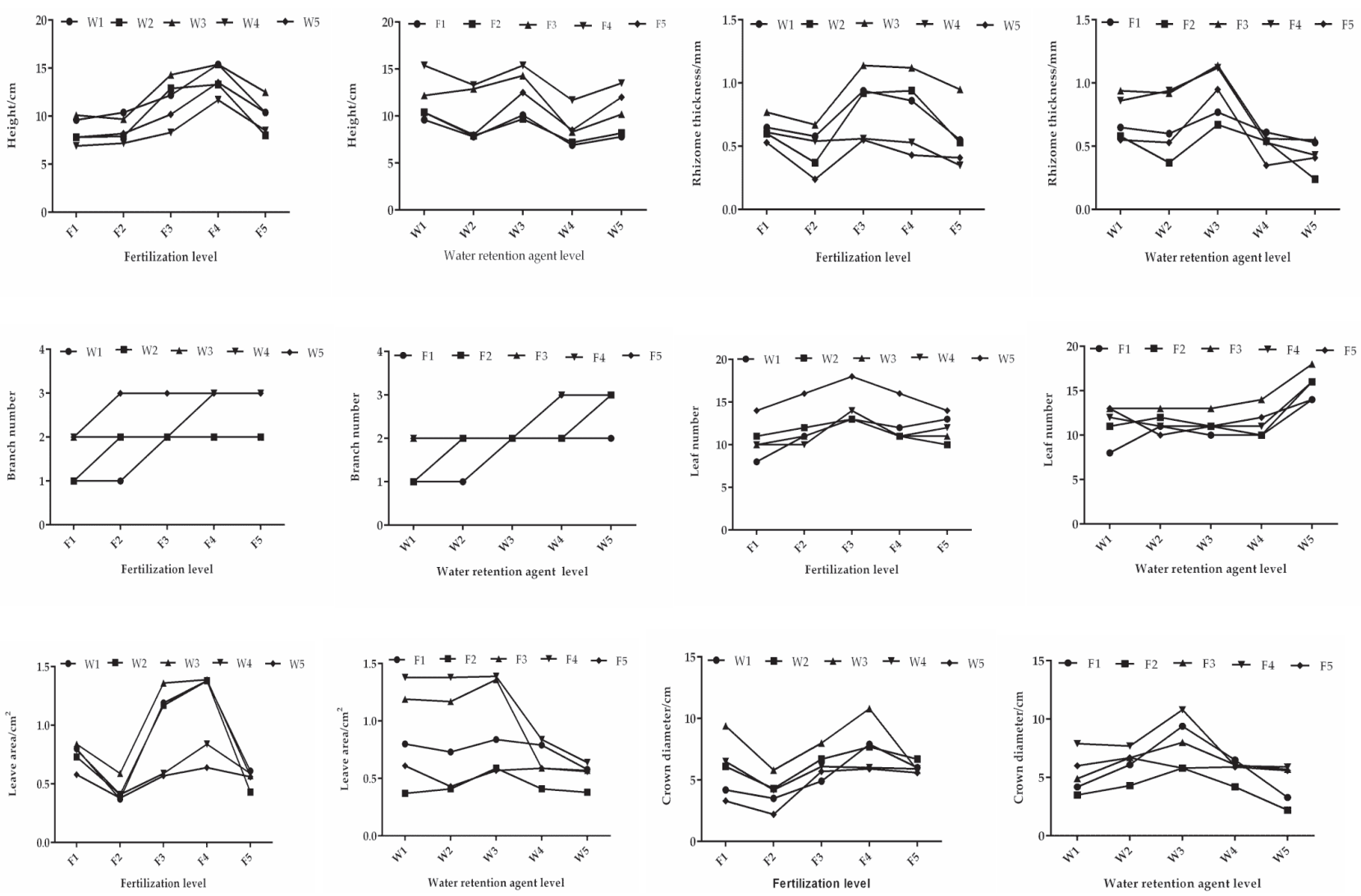

Fig. 7. Effect of water and fertilizer on plant growth index: F1-F5 and W1-W5 represent 5 different gradients of fertilizer and waterretaining agent content, respectively. 
Table 2. Comprehensive appraisal of the effects of different levels of water and fertilizer on A. fruticosa; W1-W5 and F1-F5 represent 5 different control levels of fertilizer and water-retaining agent content, respectivel.

\begin{tabular}{|c|c|c|c|c|c|c|c|c|c|c|}
\hline \multirow{2}{*}{ Item } & \multicolumn{9}{|c|}{ Control level of water and fertilizer } \\
\cline { 2 - 13 } & W1 & W2 & W3 & W4 & W5 & F1 & F2 & F3 & F4 & F5 \\
\hline Height & 0.95 & 0.77 & 1 & 0 & 0.28 & 0 & 0.14 & 0.45 & 1 & 0.14 \\
\hline Branch number & 0 & 0 & 1 & 1 & 1 & 0 & 0 & 1 & 1 & 1 \\
\hline Leaf area & 0.85 & 0.58 & 1 & 0.81 & 0 & 0.43 & 0 & 0.81 & 1 & 0.24 \\
\hline Rhizome thickness & 0.50 & 0.29 & 1 & 0.33 & 0 & 0.26 & 0.08 & 1 & 0.79 & 0 \\
\hline Leaf number & 0 & 0.50 & 0.33 & 0.33 & 1 & 0 & 0.60 & 1 & 0.80 & 1 \\
\hline Crown diameter & 0.15 & 0.46 & 1 & 0.52 & 0 & 0.16 & 0 & 0.32 & 1 & 0.57 \\
\hline Mean value of membership functions & 0.41 & 0.43 & 0.89 & 0.50 & 0.38 & 0.14 & 0.14 & 0.76 & 0.93 & 0.49 \\
\hline
\end{tabular}

in growth indices. Therefore, the amount of fertilizer applied to the substrate should be controlled as an excess of fertilizer, which may result in stunted plant growth. Similar results were reported for Populus tremuloides Michx., Pinus sylvestris L., and Picea abies L. [39-40]. In addition, the leaf number tended to increase at F3 levels of fertilizer, which is attributed to fewer nutrients leaching into the runoff and increased nutrient release from the substrate material. The water-retaining agent used in the present study is a type of high-molecular polymer that can absorb water and other molecules and ions. Many adsorbed urea molecules are released slowly from the water-retaining agent [41], and the coating of water-retaining agent will have a slow release effect on nutrients [42]. Therefore, this agent provides a new material for the design of substrate material, in which nitrogen, phosphorus, and potassium fertilizers are coated with the water-retaining agent in the substrate, creating eutrophic conditions [43]. This technology is cost-effective and easy to operate and therefore a suitable method for extended management of substrate material.

\section{Comprehensive Appraisal of Optimal Conditions of Water and Fertilizer}

In order to avoid the sidedness of single index evaluation, a method for calculating relative-membership grade was proposed to fully evaluate the effects of different levels of water and fertilizer on this shrub. Comprehensive appraisal of the substrate material effect standards was conducted by comparing the differences between each mean value of the membership function for growth index. W3F4 was identified as the optimal ratio of water and fertilizer content for effective material restoration by $A$. fruticosa (Table 2). These results were consistent with the results obtained in field experiments. It was also demonstrated that higher content of water and fertilizer does not benefit plant growth. Furthermore, plant type is an important factor that affects nutrient runoff, absorption of nutrients, permeability and porosity of the substrate material, and the effects of plant roots on the soil microbial community [44]. In the second year, plant biomass of $A$. fruticosa becomes relatively stable, the plant's demand for nutrients is reduced, and the major elements accumulated in the substrate are gradually released in the runoff [45].

Function analysis was conducted to calculate the relationship coefficients between fertilizer, waterretaining agent, and plant growth index. According to Table 3, the maximum number of leaves was obtained at F3 and W5, while the other plant growth parameters performed the best at W3 or F4. The combination of W3F4 was the optimal formulation in substrate material for plant growth based on overall costs. This combination accounts for the losses due to runoff from the substrate

Table 3. Relationship between fertilizer concentration, water retaining agent levels, and plant growth index; F3, F4 and W3, W5 represent different control levels of water and fertilizer, respectively.

\begin{tabular}{|c|c|c|c|c|}
\hline Item & Regression model & $\mathrm{R}^{2}$ & \multicolumn{2}{|c|}{ Optimal concentration } \\
\hline Height & $\mathrm{y}=-0.6071 x^{2}+4.6929 x+5$ & 0.6423 & $\mathrm{~F} 4$ & $\mathrm{~W} 3$ \\
\hline Branch number & $\mathrm{y}=0.0714 x^{2}-0.1286 x+2$ & 0.8095 & $\mathrm{~F} 4$ & $\mathrm{~W} 5$ \\
\hline Leaf area & $\mathrm{y}=-0.0686 \mathrm{x}^{2}+0.2094 x+1.2520$ & 0.9171 & $\mathrm{~F} 4$ & $\mathrm{~W} 3$ \\
\hline Rhizome thickness & $\mathrm{y}=-0.0557 x^{2}+0.2203 x+0.7740$ & 0.6488 & $\mathrm{~F} 3$ & $\mathrm{~W} 3$ \\
\hline Leaf number & $\mathrm{y}=0.6429 x^{2}-2.7571 x+15.4000$ & 0.9514 & F3 & W5 \\
\hline Crown diameter & $\mathrm{y}=-0.5500 x^{2}+2.7300 x+5.5200$ & 0.4745 & F4 & W3 \\
\hline
\end{tabular}



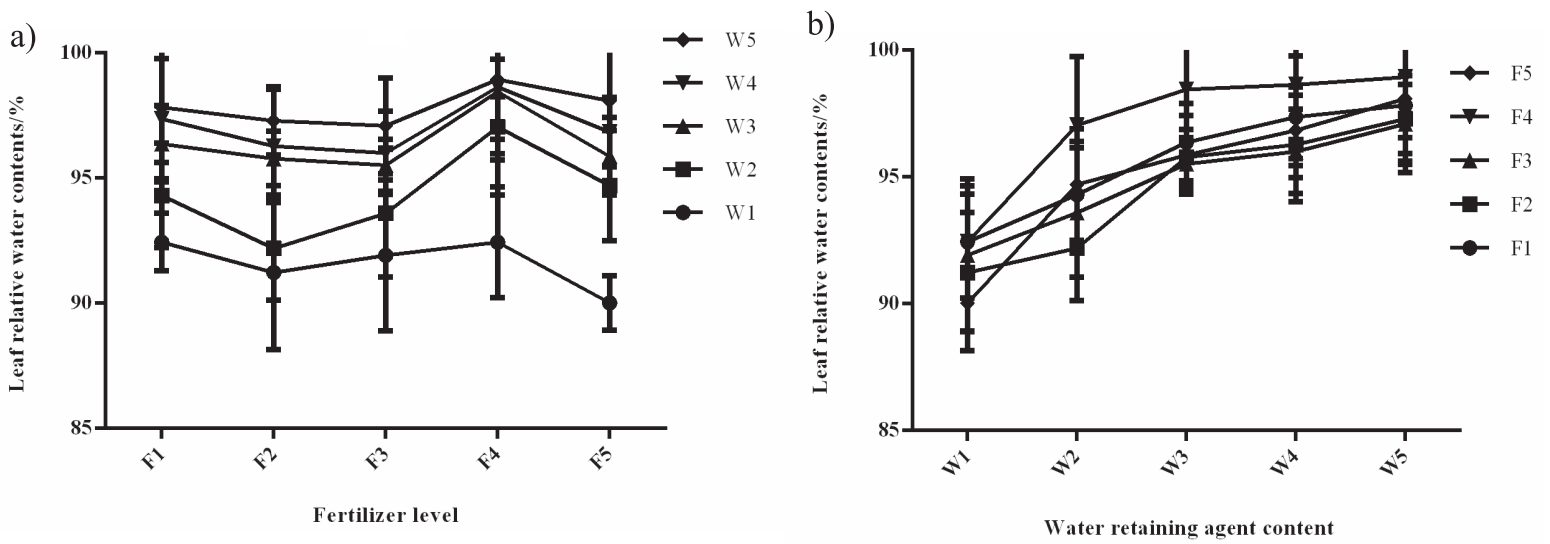

Fig. 8. Water content in plant leaves under different water and fertilizer concentrations: F1-F5 and W1-W5 represent 5 different control levels of fertilizer and water-retaining agent content, respectively; uncertainty is given as the standard deviation of the mean of 3 replicated plots.

material and provides optimal conditions under which the plant can absorb more nutrients and thus improve plant growth indices.

In slope ecological engineering, artificial materials (such as the substrate material used in the present study) are often used instead of natural soil [46-47]. Researchers [48] have reported that artificial soil has many advantages compared to natural soil, including rich nutrition, good stability, and anti-erosion ability. Therefore, the present research on nutrient losses and material formulation will help to further develop the ecological engineering of rock slopes. The results presented herein show that the capability of substrate to hold nutrients have decreased with service time (Figs 5-6). This problem can be resolved by adding more fertilizer to the soil, which will extend the service life of the substrate material. However, higher levels of fertilizer in the substrate material will accelerate the initial rate of fertilizer loss, thereby reducing the amount of utilized fertilizer. Moreover, excessive nutrients prevent seed germination and plant growth. For example, at F4 fertilizer concentration and constant water-retaining agent level, the nitrogen loss from the substrate material increased, which ultimately affected the growth rate of this shrub and resulted in small oblong leaves. At higher fertilizer levels, phosphorus loss followed the same trend observed for the growth of crown diameter, suggesting a positive correlation between phosphorus loss and crown diameter growth. At the same time, phosphorus in the substrate material affects plant height [49]. Based on the one-yearlong observations, the biomass of $A$. fruticosa was stable. Nitrogen, phosphorus, and potassium in this species are mainly absorbed by plant roots in the form of inorganic nutrients. Although these nutrients are abundant in the substrate material, they are not fully absorbed and utilized by plant roots as their content in plants depends on the plants' internal demands; the excess of nutrients, which is relatively large, is lost in runoff. Substrate material absorbs the nutrients from the fertilizers, thus improving its anti-leaching property. Moreover, water- retaining agent could set up and stabilize the water-stable aggregates and attract and hold the 3 primary nutrients in the fertilizer from the substrate material, which further inhibits the losses of available nutrient elements from the fertilizer [50]. At present, the service life of substrate material in rock slopes is not long - only up to 5 years and new technologies should be developed to extend its service life.

\section{Water-Holding Capacity of Leaves}

The water-holding capacity of plant leaves is an indicator of plant drought resistance. As fertilizer concentration increased from F1 to F2 while keeping the water-retaining agent levels constant, the relative water content of leaves decreased by 2.2\% (at W2), 1.3\% (at W1), $1.1 \%$ (at W4), $0.06 \%$ (at W3), and $0.05 \%$ (at W5; Fig. 8a). The leaf relative water content increased with increasing water-retaining agent levels from W1 to W5 under constant fertilizer concentration, reaching the highest levels of $92.43 \%, 97.03 \%, 98.46 \%, 98.63 \%$, and $98.93 \%$, respectively, at F3 fertilizer concentration. However, these water levels decreased when the amount of fertilizer was kept constant at the F5 level. The probable reason underlying this decrease is that rising fertilizer concentrations cause nutrient excess in the substrate material, decreasing the water and nutrient absorption by A. fruticosa from the water-retaining agent. The relative water contents in the substrate material increased and leveled off with ascending water-retaining agent contents under constant fertilizer levels (Fig. 8b). As the waterretaining agent level increased from $\mathrm{W} 1$ to $\mathrm{W} 2$, the relative water content of leaves ascended gradually, especially at F1 fertilizer concentration; its relative change rate was $19.8 \%$. Therefore, it is important to recognize that processes involved in water accumulation in the substrate material related to the water-retaining agent play an important role in the absorption of water and nutrients by plant roots and rocky slope eco-engineering protection [51]. 
Increased contents of water-retaining agent gradually increased the water levels in the substrate material and plant body. This led to a rise in the water content of plant leaves, in accordance with the previous findings [52]. The application of water-retaining agents can reduce soil water evaporation and supply the water needed for plant growth. In addition, increased water-retaining agent levels keep the water budget for plant growth and render the plants less vulnerable to drought stress [53]. Furthermore, the ratio of water to fertilizer is an important parameter to consider in the application of substrate material, and our data indicate that $\mathrm{W} 3 \mathrm{~F} 4$ presents an optimal ratio.

\section{Conclusions}

Potassium concentration in runoff was significantly higher than concentrations of other nutrients at different fertilizer levels. The growth of $A$. fruticosa was related to fertilizer input costs at different applications of waterretaining agent. Normally, rainfall is likely to cause soil erosion on slopes, which can be prevented by planting substrate material on slopes as part of the ecological restoration program. Substrate material not only ensures healthy plant growth, but also prevents eutrophication of water systems caused by nutrients brought in by substrate runoff after rainfall. However, due to limitations of experimental conditions, other factors of substrate material were not considered in this study, for example, slope length, rainfall characteristics, and vegetation coverage. As a result, W3F4 was the most favorable combination of fertilizer and water-retaining agent levels for plant growth. Because the results of this combination might be different than the results that one might see on real constructed rocky slopes, more research needs to be performed to determine proper levels of fertilizer and water-retaining agent and to verify the effect on plant growth. Overall, the results of this study are expected to promote substrate material application in steep rocky slope stabilization projects to reduce nutrient losses and soil erosion of substrate material.

\section{Acknowledgements}

This study was financially supported by the National Key Research and Development Program of China (2016YFD0600203) and the National Key Research Projects of China (2016YFC0206006). We are grateful to all of the reviewers and editors for reading the manuscript and providing useful comments.

\section{References}

1. CHEN Z., YANG L.X., JIANG Z.Q., LI C.J., HU X., PANG L., LI S.C., SUN H.L. Runoff-driven nitrogen and phosphorus dynamics of substrate material for rocky slope eco-engineering. Ecological Engineering. 51 (1), 123, 2013.
2. YOUSSEF A.M., PRADHAN B., AL-HARTHI S.G. Assessment of rock slope stability and structurally controlled failures along Samma escarpment road, Asir Region (Saudi Arabia). Arabian Journal of Geosciences. 8 (9), 6835, 2015.

3. NAGHDI R., MALEKI S., ABDI E., MOUSAVI R., NIKOOY M. Assessing the effect of Alnus roots on hillslope stability in order to use in soil bioengineering. Journal of Forest Science. 59 (59), 417, 2013.

4. KOZUHAROVA E., MATKOWSKI A.M., WOZNIAK D., SIMEONOVA R., NAYCHOV Z., MALAINER C., MOCAN A., NABAVI S.M., ATANASOV A.G. Amorpha fruticosa - A noxious invasive alien plant in Europe or a medicinal plant against metabolic disease?. Frontiers in Pharmacology. 8, 333, 2017.

5. SHI X., CHEN Y.T., WANG S.F., PAN H.W., SUN H.J., LIU C.X., LIU J.F., JIANG Z.P. Phytoremediation potential of transplanted bare-root seedlings of trees for lead/zinc and copper mine tailings. International Journal of Phytoremediation. 18 (11), 1155, 2016.

6. MITROVIC M., JARIC S., KOSTIC O., GAJIC G., KARADZIC B., DJURDJEVIC L.L., OBERAN L., PAVlOVIC D., PAVLOVIC M., PAVLOVIC P. Photosynthetic efficiency of four woody species growing on fly ash deposits of a Serbian 'Nikola Tesla - A' thermoelectric plant. Polish Journal of Environmental Studies. 21 (5), 1339, 2012.

7. ZHANG X.R., TAN X.F., WANG R.Q., XU N.N., GUO W.H. Effects of soil moisture and light intensity on ecophysiological characteristics of Amorpha fruticosa seedlings. Journal of Forestry Research. 24 (2), 293, 2013.

8. BRIGIC A., VUJCIC-KARLO S., KEPCIJA R.M., STANCIC Z., ALEGRO A., TERNJEJ I. Taxon specific response of carabids (Coleoptera, Carabidae) and other soil invertebrate taxa on invasive plant Amorpha fruticosa in wetlands. Biological Invasions. 16 (7), 1497, 2014.

9. KRPAN A.P.B., TOMAŠIĆ Z., ZECIC Z., DIJANA V. Bioproductivity of indigobush (Amorpha fruticosa L.) in one-year, two-year and four-year rotation. Sumarski List. 139 (3), 123, 2015.

10. HOVANET M.V., MARINAS I.C., DINU M., OPREA E., CHIFIRIUC M.C., STAVROPOULOU E., LAZAR V. The phytotoxicity and antimicrobial activity of Amorpha fruticosa L. leaves extract. Romanian Biotechnological Letters. 20 (4), 10670, 2015

11. WEI Q., WEI Y., WU H.W., YANG X.Y., CHEN H.L., ZHANG H.X. Chemical composition, anti-oxidant, and antimicrobial activities of four saline-tolerant plant seed oils extracted by SFC. Journal of the American Oil Chemists Society. 93 (9), 1173, 2016.

12. MUHARINI R., DIAZ A., EBRAHIM W., MANDI A., KURTAN T., REHBERG N., KALSCHEUER R., HARTMANN R., ORFALI R.S., LIN W.H. Antibacterial and cytotoxic phenolic metabolites from the fruits of Amorpha fruticosa. Journal of Natural Products. 80 (1), 169, 2017.

13. TAKAGI K., HIOKI Y. Autecology, distributional expansion and negative effects of Amorpha fruticosa L. on a river ecosystem: a case study in the Sendaigawa River, Tottori Prefecture. Landscape and Ecological Engineering. 9 (1), 175, 2013.

14. YAN W., ZHONG Y., SHANGGUAN Z.P. Rapid response of the carbon balance strategy in Robinia pseudoacacia and Amorpha fruticosa to recurrent drought. Environmental and Experimental Botany. 138, 46, 2017. 
15. FAN J.C., HUANG C.L., LIAO K.W., LIAO W.W. Effect evaluation of shotcrete vegetation mulching technique applied to steep concrete-face slopes on a highway of Taiwan. Paddy and Water Environment. 11 (1-4), 145, 2013.

16. CHEN F., XU Y., WANG C., MAO J. Effects of concrete content on seed germination and seedling establishment in vegetation concrete matrix in slope restoration. Ecological Engineering. 58, 99, 2013.

17. BAO X., LIAO W., DONG Z., WANG S., TANG W. Development of vegetation-pervious concrete in grid beam system for soil slope protection. Materials. 10 (2), 96, 2017.

18. HUANG Z.Y., CHEN J., AI X.Y., LI R.R., AI Y.W., LI W. The texture, structure and nutrient availability of artificial soil on cut slopes restored with OSSS - influence of restoration time. Journal of Environmental Management, 200, 502, 2017.

19. LI S.F., LI Y.W., SHI J.L., ZHAO T.N., YANG J.Y. Optimizing the formulation of external-soil spray seeding with sludge using the orthogonal test method for slope ecological protection. Ecological Engineering. 102, 527, 2017.

20. YANG L.X., LI S.C., SUN H.L., YE F.F., LIU W., LUO S. Polyacrylamide molecular formulation effects on erosion control of disturbed soil on steep rocky slopes. Canadian Journal of Soil Science. 91 (6), 917, 2017.

21. LI S.C., SUN H.L., LONG F., LI F.B. Greening Roll, U.S. Patent 9167743B2, 2015.

22. SONG H.F., LI S.C., SUN H.L., LIU J.Y., CHEN Y.H. Effects of soil-applied paclobutrazol on growth and physiological characteristics of Amorpha fruticosa. Plant Physiology Communications. 51 (9), 1495, 2015 [In Chinese].

23. SCHMITT L., RIVIERE J.N. Comparative life-history traits of two Syzygium species (Myrtaceae): one invasive alien in La Reunion, the other native. Acta Botanica Gallica. 149 (4), 457, 2002.

24. SADEGHISHOAE M., PAKNEJAD F., SHAHBAZPANAHI B., TOOKALLOO M.R. Florescence parameters, chlorophyll content and relative water content (RWC) of wheat varieties as affected by different regimes of irrigation. International Journal of Biosciences. 4 (5), 135, 2014.

25. SENER E., SEHNAZ S. Evaluation of groundwater vulnerability to pollution using fuzzy analytic hierarchy process method. Environmental Earth Sciences. 73 (12), 8405, 2015.

26. YU N., ZHANG Y.L., ZOU H.T., HUANG Y., ZHANG Y.L., DANG X.L., YANG D. Fuzzy evaluation of different irrigation and fertilization on growth of greenhouse tomato. Fuzzy Information and Engineering, CAO B.Y., Eds., Springer: Berlin Heidelberg, Germany, 40, 980, 2007.

27. RASHID M., REHMAN O., ALVI S., KAUSAR R., AKRAM M.I. The effectiveness of soil and water conservation terrace structures for improvement of crops and soil productivity in rainfed terraced system. Pakistan Journal of Agricultural Sciences. 53 (1), 241, 2016.

28. WOOD T.E., MATTHEWS D., VANDECAR K., LAWRENCE D. Short-term variability in labile soil phosphorus is positively related to soil moisture in a humid tropical forest in Puerto Rico. Biogeochemistry. 127 (1), 35, 2016.

29. MENDES W.D.C., ALVES J.J., CUNHA P.C.R.D., SILVA A.R.D., EVANGELISTA A.W.P., CASAROLI D. Potassium leaching in different soils as a function of irrigation depths. Revista Brasileira De Engenharia Agricola E Ambiental. 20 (11), 972, 2016.
30. REILLY A.M.O., WANIELISTA M.P., CHANG N.B., XUAN Z., HARRIS W.G. Nutrient removal using biosorption activated media: Preliminary biogeochemical assessment of an innovative stormwater infiltration basin. Science of the Total Environment. 432 (16), 227, 2012.

31. SMITH D.R., WARNEMUENDE-PAPPAS E.A. Vertical tillage impacts on water quality derived from rainfall simulations. Soil and Tillage Research. 153, 155, 2015.

32. TAN X.Z., SHAO D.G., LIU H.H, YANG F.S., XIAO C., YANG H.D. Effects of alternate wetting and drying irrigation on percolation and nitrogen leaching in paddy fields. Paddy and Water Environment. 11 (1-4), 381, 2013.

33. LETSCHER R.T., HANSELL D.A., KADKO D., BATES N.R. Dissolved organic nitrogen dynamics in the Arctic Ocean. Marine Chemistry. 148 (148), 1, 2013.

34. WEN X.X., ZHANG D.Q., LIAO Y.C., JIA Z.K., JI S.Q. Effects of water-collecting and -retaining techniques on photosynthetic rates, yield, and water use efficiency of millet grown in a semiarid region. Journal of Integrative Agriculture. 11 (7), 1119, 2012.

35. TIAN C., ZHOU X., LIU Q., PENG J.W., WANG W.M., ZHANG Z.H., YANG Y., SONG H.X., GUAN C.Y. Effects of a controlled-release fertilizer on yield, nutrient uptake, and fertilizer usage efficiency in early ripening rapeseed (Brassica napus L.). Journal of Zhejiang UniversityScience B. 17 (10), 775, 2016.

36. ARIBAL L.G., BONGGAY J.G., FERNANDO E.S. Leaf size indices and structure of the peat swamp forest. Global Journal of Environmental Science and Management. 3 (1), 63, 2017.

37. DIAZ-PEREZ J.C., HOOK J.E. Plastic-mulched bell pepper (Capsicum annuum L.) plant growth and fruit yield and quality as influenced by irrigation rate and calcium fertilization. Hortscience. 52 (5), 774, 2017.

38. MANZONI S., VICO G., PALMROTH S., PORPORATO A., KATUL G. Optimization of stomatal conductance for maximum carbon gain under dynamic soil moisture. Advances in Water Resources. 62 (4), 90, 2013.

39. SCHOTT K.M., PINNO B.D., LANDHAUSSER S.M. Premature shoot growth termination allows nutrient loading of seedlings with an indeterminate growth strategy. New Forests. 44 (5), 635, 2013.

40. FREDRIK F., JOACHIM S., ANNIKA N. Residual long-term effects of forest fertilization on tree growth and nitrogen turnover in boreal forest. Forests. 6 (4), 1145, 2015.

41. TAN B.K., CHEE Y., GAN S.N., ROZALI S. Biodegradable mulches based on poly(vinyl Alcohol), kenaf fiber, and urea. Bioresources. 10 (3), 5532, 2015.

42. ZHOU L.L., CAI D.Q., HE L., ZHONG N.Q., YU M., ZHANG X., WU Z.Y. Fabrication of a high-performance fertilizer to control the loss of water and nutrient using micro/nano networks. Acs Sustainable Chemistry and Engineering. 3 (4), 645, 2015.

43. RASHIDZADEH A., OLAD A., REYHANITABAR A. Hydrogel/clinoptilolite nanocomposite-coated fertilizer: swelling, water-retention and slow-release fertilizer properties. Polymer Bulletin. 72 (10), 2667, 2015.

44. MILANDRI S.G., WINTER K.J., CHIMPHANGO S.B. M., ARAMITAGE N.P., MBUI D.N., JACKSON G.E., LIEBAU V. The performance of plant species in removing nutrients from stormwater in biofiltration systems in Cape Town. Water SA. 38 (8), 655, 2012.

45. LOURENZI C.R., CERETTA C.A., CERINI J.B., FERREIRA P.A.A., LORENSINI F., GIROTTO E., TIECHER T.L., SCHAPANSKI D.E., BRUNETTO 
G. Available content, surface runoff and leaching of phosphorus forms in a typic hapludalf treated with organic and mineral nutrient sources. Revista Brasileira De Ciência Do Solo. 38 (2), 544, 2014.

46. SPARGO A., DOLEY D. Selective coal mine overburden treatment with topsoil and compost to optimise pasture or native vegetation establishment. Journal of Environmental Management. 182, 342, 2016.

47. XU H., LI T.B., CHEN J.N., LIU C.N., ZHOU X.H., XIA L. Characteristics and applications of ecological soil substrate for rocky slope vegetation in cold and high-altitude areas. Science of the Total Environment. 609, 446, 2017.

48. AI Y.W., CHEN Z.Q., GUO P.J., ZENG L.X., LIU H., DA Z.J., LI W. Fractal characteristics of synthetic soil for cut slope revegetation in the purple soil area of China. Canadian Journal of Soil Science. 92 (2), 277, 2012.

49. MACIL P.J., OGOLA J.B.O., ODHIAMBO J. J.O., LUSIBA S.G. The response of some physiological traits of chickpea (Cicer arietinum L.)to biochar and phosphorus fertilizer application. Legume Research. 40 (2), 299, 2017.
50. ZHOU L.L., CAI D.Q., HE L.L., ZHONG N.Q., YU M., ZHANG X., WU Z.Y. Fabrication of a high-performance fertilizer to control the loss of water and nutrient using micro/nano networks. Acs Sustainable Chemistry and Engineering. 3 (4), 645, 2015.

51. YANG L., YANG Y., CHEN Z., GUO C., LI S. Influence of super absorbent polymer on soil water retention, seed germination and plant survivals for rocky slopes ecoengineering. Ecological Engineering. 62 (1), 27, 2014.

52. HUANG C.W., DOMEC J.C., WARD E.J., DUMAN T., MANOLI G., PAROLARI A.J., KATUL G.G. The effect of plant water storage on water fluxes within the coupled soilplant system. The New Phytologist. 213 (3), 1093, 2017.

53. WEI J., YANG H.Y., HUI C., TAN T.W. Using polyaspartic acid hydro-gel as water retaining agent and its effect on plants under drought stress. Saudi Journal of Biological Sciences. 23 (5), 654, 2016. 